\title{
Technical Note: Evaporation of polar stratospheric cloud particles, in situ, in a heated inlet
}

\author{
T. Eidhammer and T. Deshler \\ University of Wyoming, Department of Atmospheric Science, USA \\ Received: 26 April 2004 - Published in Atmos. Chem. Phys. Discuss.: 27 September 2004 \\ Revised: 4 January 2005 - Accepted: 13 January 2005 - Published: 21 January 2005
}

\begin{abstract}
In December 2001 and 2002 in situ aerosol measurements were made from balloon-borne platforms within polar stratospheric clouds (PSC) which contained particles of supercooled ternary solution (STS), nitric acid trihydrate (NAT) and ice. Particle size (radius $>0.15 \mu \mathrm{m}$ ) and number concentrations were measured with two optical particle counters. One of these included an $\sim 80 \mathrm{~cm}$ inlet heated to $>244 \mathrm{~K}$ to evaporate the PSC particles and thus to obtain measurements, within PSCs, of the size distribution of the particles upon which the PSCs condensed. These measurements are compared to models, described here, that calculate the evaporation of PSC particles at $\sim 250 \mathrm{~K}$ and $\sim 290 \mathrm{~K}$ for an inlet transition time of about $0.1 \mathrm{~s}$. The modeled evaporation for STS agrees well with the measurements. For NAT the modeled evaporation is less than the evaporation measured. The primary uncertainty concerns the phase and morphology of NAT particles as they are brought to temperatures $>50 \mathrm{~K}$ above equilibrium temperatures for NAT at stratospheric partial pressures. The slow evaporation of NAT in heated inlets could be used to identify a small NAT component within a mixed phase PSC dominated by STS.
\end{abstract}

\section{Introduction}

In the stratosphere, chemical reactions occur on PSC particles, leading to ozone depletion (Solomon et al., 1986; Tolbert et al., 1988). These particles are composed of water and nitric acid and are observed in three phases in the stratosphere: 1) Nitric acid trihydrate (NAT), a stable solid particle (Hanson and Mauersberger, 1988b; Voigt et al., 2000; Fahey et al., 2001), 2) Supercooled ternary solution (STS), a liquid particle (Dye et al., 1992; Tabazadeh et al., 1994; Carslaw et al., 1994; Schreiner et al., 1999), 3) Ice (Goodman et al.,

Correspondence to: T. Eidhammer

(trude@uwyo.edu)
1989, 1997; Deshler et al., 2003b). All these particles form on the ubiquitous stratospheric sulfate aerosol (SSA) which consist of water and sulfuric acid. This paper seeks to contribute to our understanding of the growth of these particles by an analysis of in situ PSC measurements in the Arctic in December 2001 and 2002 (Deshler et al., 2003b; Larsen et al., 2004).

Size (radius $>0.15 \mu \mathrm{m}$ ) and number concentrations were measured with two optical particle counters (OPC) (Deshler et al., 2003a). One OPC provided PSC particle size distribution measurements. The second OPC included either an $82 \mathrm{~cm}$ inlet, with a $90^{\circ}$ bend, heated to between $244 \mathrm{~K}$ and $256 \mathrm{~K}$ (2001), or a $75 \mathrm{~cm}$ straight inlet heated to between $262 \mathrm{~K}$ and $300 \mathrm{~K}$ (2002). The heated inlet was used to obtain measurements, within PSCs, of the size distribution of SSA. This size distribution is required to initialize microphysical models of PSC growth. Here we have developed STS- and NAT- evaporation models which simulate the evaporation of particles in the heated inlet at $\sim 250 \mathrm{~K}$ and $\sim 290 \mathrm{~K}$ in a time period of about $0.1 \mathrm{~s}$. Results from this model are compared with the heated inlet OPC observations.

Other non-equilibrium models simulate, in lee wave clouds, growth and evaporation of STS particles (Meilinger et al., 1995), growth, evaporation and freezing of STS particles as well as formation and growth of solid particles (e.g. Carslaw et al., 1998; Luo et al., 2003; Larsen et al., 2004). The heating/cooling rates in these models are on the order of $5-80 \mathrm{~K} /$ hour while the heating rate in the heated inlet is $\sim 1.5 \times 10^{7} \mathrm{~K} /$ hour. The basic equations for the growth/evaporation of the particles in these models are the same as in our model; however, we do not consider nucleation or freezing of particles since our model is an evaporation model at temperatures much higher than the formation temperature of NAT. While we follow a particle in the inlet, the other non-equilibrium models follow air parcel trajectories. The models described in Meilinger et al. (1995), Carslaw et al. (1998), Luo et al. (2003) and Larsen

(C) 2005 Author(s). This work is licensed under a Creative Commons License. 
et al. (2004) are all Lagrangian or quasi-Lagrangian in radius space just as the model described here. However, direct comparison of these non-equilibrium models with the model described here can not be conducted since the lee-wave models concentrate on supersaturation cases, while our model is made for high subsaturation cases, and our heating rates far exceed anything found in the natural systems being described by the other non-equilibrium models.

\section{Model description}

Evaporation of PSC particles is controlled by diffusion of two molecular species $\left(\mathrm{H}_{2} \mathrm{O}\right.$ and $\left.\mathrm{HNO}_{3}\right)$ away from the particle. The governing equation is

$a \frac{d a}{d t}=\frac{C}{R \rho} \sum_{i} D_{i}^{\star} M_{i}\left(\frac{P_{p, i}}{T_{\infty}}-\frac{P_{s, i}}{T_{a}}\right)$.

Here $a$ is the radius of the particle, $D^{\star}$ the modified diffusion coefficient, $C$ the capacitance, $M$ the molecular weight of the evaporating species, $R$ universal gas constant, $\rho$ the density of the particle, $P_{p}$ the partial pressure of the evaporating species from the particle and $P_{S}$ the saturation vapor pressure of the same particle. $T_{\infty}$ is the mean temperature of the air in the inlet and $T_{a}$ is the temperature of the evaporating particle. The subscript $i$ stands for the evaporating species $\mathrm{H}_{2} \mathrm{O}$ or $\mathrm{HNO}_{3}$. In this paper the subscripts $n=\mathrm{HNO}_{3}, w=\mathrm{H}_{2} \mathrm{O}$ and $s=\mathrm{H}_{2} \mathrm{SO}_{4}$. The modified diffusion coefficient $D^{\star}$ accounts for molecular discontinuities near the particles with a multiplicative function, $\Gamma(K n)$, where

$\Gamma(K n)=\frac{1}{1+C \lambda(K n) K n}$.

This approach to find $D^{\star}$ is described by Fuchs and Sutugin (1971). Here $K n=\Lambda / a$ is the Knudsen number for diffusion and $\Lambda$ is the mean free path of the evaporating species. The mean free path is found by multiplying the mean free path of air with a correction factor $\Theta$ (Hamill et al., 1977; Larsen, 2000). For $\mathrm{H}_{2} \mathrm{O}, \Theta_{w}=0.820$ and for $\mathrm{HNO}_{3}, \Theta_{n}=0.857$. The function $\lambda(K n)$ in Eq. (2) is given by

$\lambda(K n)=\frac{1.33+\frac{0.71}{K n}}{1+\frac{1}{K n}}$

(Fuchs and Sutugin, 1971). The sticking- and thermalaccommodation coefficients are here assumed to be unity and are not included in Eq. (3). The assumption of unity for the accommodation coefficients is based on Pruppacher and Klett (1997) for $\mathrm{H}_{2} \mathrm{O}$ and a lack of information for $\mathrm{HNO}_{3}$.

As the particle evaporates, the particle temperature, $T_{a}$, decreases due to release of latent heat $L$. If $T_{\infty} \approx T_{a}$, the Maxwell-Mason equation can be used to calculate the evaporation rate analytically (e.g. Pruppacher and Klett, 1997). However, in our case $T_{a}$ is significantly lower than $T_{\infty}$ in most of the inlet and the particle temperature must be calculated numerically. $T_{a}$ is calculated from the conductive heat transfer equation:

$\frac{d q}{d t}=4 \pi a k^{\star}\left(T_{\infty}-T_{a}\right)=-4 \rho \pi L a^{2} \frac{d a}{d t}$.

Here $k^{\star}$ is the modified thermal conductivity. Inserting (1) into (4) gives

$T_{\infty}-T_{a}+\frac{C}{R k^{\star}} \sum_{i} D_{i}^{\star} w_{i} L_{i} M_{i}\left(\frac{P_{p, i}}{T_{\infty}}-\frac{P_{s, i}}{T_{a}}\right)=0$,

where $w$ is the mass fraction of the evaporating species and arrives from the weighting of the latent heat for the different evaporating species.

The latent heat of vaporization and sublimation is calculated from the Clausius-Clapeyron equation. As for the diffusion coefficient, the thermal conductivity, $k$, must also be modified due to discontinuities near the particle and $k$ is multiplied with the $\Gamma$-function given in (2). The Knudsen number for thermal conductivity is:

$K n_{t}=\frac{3 k M_{a}}{\rho_{a} v_{a}\left(\frac{c_{p}}{R_{d}}-0.5 R\right) a}$

(e.g. Toon et al., 1989). Here $M_{a}$ and $\rho_{a}$ are the molecular weight and density of air, $v_{a}$ the thermal velocity of air molecules, $c_{p}$ the specific heat at constant pressure and $R_{d}$ the gas constant for dry air. For particles less than approximately $0.05 \mu \mathrm{m}$ the Kelvin effect on the vapor pressure must be included.

The air entering the inlet is increasing in temperature as it is brought through the inlet. The mean air temperature, $T_{m}$, as a function of location in the inlet, $x$, can be expressed

$T_{m}(x)=T_{w}-\left(T_{w}-T_{i}\right) e^{-h p x / \dot{m} c_{p}}$

(e.g. Bejan, 1984). Here $T_{w}$ is the temperature of the inlet wall, $T_{i}$ the temperature of air as it enters the inlet, $p$ the perimeter, $\dot{m}$ the mass flow rate and $h$ is the heat transfer coefficient.

The heated inlet in 2001 had a $90^{\circ}$ bend. As particles flow through the bend, the largest particles will be deposited on the wall. The fraction of particles not lost in the bend, $B$ is given by

$B=1-\frac{\pi}{2}\left(\operatorname{Stk}\left(\rho, a, C_{c}, u, v, d\right)\right)$,

where Stk is the Stokes number (Hinds, 1999) and $C_{c}$ the pressure dependent slip correction factor. The expression for $C_{c}$ used here is also given in Hinds (1999). $u$ is the mean air velocity in the inlet, $v$ the viscosity of the air and $d$ is the diameter of the inlet. The flow in the inlet is laminar and deposition in the straight part of the inlet is not expected.

In applying this model, most parameters and variables are well known or specified. The primary exceptions are vapor pressures of $\mathrm{HNO}_{3}$ and $\mathrm{H}_{2} \mathrm{O}$ over NAT for high temperatures, but with stratospheric partial pressure in the ambient air. 


\subsection{Details of the STS model}

To model the evaporation of STS, a thermodynamic model developed by Carslaw et al. (1995) and Clegg et al. (1998) is used to calculate the vapor pressure of $\mathrm{H}_{2} \mathrm{O}$ and $\mathrm{HNO}_{3}$ over the STS particle. As STS evaporates it will reach a binary mode when all the $\mathrm{HNO}_{3}$ is evaporated. The same model is used for $w_{s}<0.8$ in the binary mode. For $w_{s}>0.8$ the expression given by Gmitro and Vermeulen (1964) and tabulated data from Giaugue et al. (1960) are used. The density of STS particles is found from Luo et al. (1996). For the smallest particles $(a<0.05 \mu \mathrm{m})$ the Kelvin effect, a function of the surface tension between the particle and the air, is included. The surface tension between STS and air is calculated from a molality weighted average of the binary sulfuric acid solution surface tension (Tabazadeh et al., 2000) and the binary nitric acid solution surface tension (Granzhan and Laktionova, 1975). Since STS are liquid particles, the capacitance $C$ (included in Eq. (1) and in the modification of $D$ and $k$ ) is 1 . The diffusion coefficient of $\mathrm{HNO}_{3}$ is given as $D_{n}=0.559 D_{w}$ (Larsen, 2000) where $D_{w}$ is the diffusion coefficient of $\mathrm{H}_{2} \mathrm{O}$. The mass fraction $(w)$ of $\mathrm{H}_{2} \mathrm{O}$ and $\mathrm{HNO}_{3}$ in the STS particle, required as initial conditions, is available from measurements in the PSC with a mass spectrometer (Schreiner et al., 2002; Deshler et al., 2003b). $w_{s}$ in the particles was calculated based upon measurements from the two OPCs and the assumptions that for SSA at $247 \mathrm{~K}, w_{s}=0.86$ (Steele and Hamill, 1981), and that the size distribution of SSA has a single mode.

We have assumed a $\mathrm{H}_{2} \mathrm{O}\left(\mathrm{HNO}_{3}\right)$ gas phase mixing ratio of $5 \mathrm{ppmv}(10 \mathrm{ppbv})$ to initialize the $\mathrm{H}_{2} \mathrm{O}\left(\mathrm{HNO}_{3}\right)$ partial pressure. The partial pressures are assumed to be constant in the inlet since the temperature in the inlet increases rapidly and the difference in saturation vapor pressure and partial pressure becomes quickly large. Therefore, any changes in partial pressure in the inlet will not affect particle evaporation in the inlet. The size distributions used to initialize the model are the bimodal lognormal fits from observed distributions with the ambient inlet OPC.

As STS evaporates, $w_{n}, w_{w}$ and $w_{s}$ will change. This leads to changes in the saturation vapor pressures and latent heat. The decrease in radius also leads to changes in the modified diffusion coefficient and the modified thermal conductivity. Evaporation of mass requires latent heat, thus the temperature of the particle changes during evaporation.

Equation (1) is a complicated function of radius and must be solved numerically. We here integrate Eq. (1) over time steps, $d t=2 \times 10^{-4} \mathrm{~s}$. The selection of the time step was based on the longest time interval that provided convergence. We assume that $a \frac{d a}{d t}=K(d t)$ is constant over this time step:

$$
\int_{a_{0}}^{a_{i}} a d a=\int_{0}^{d t} K_{i}(d t) d t
$$

$\Downarrow$ $a_{i}=\sqrt{a_{0}^{2}+2 K_{i}(d t) d t}$.

Here $i$ is $\mathrm{H}_{2} \mathrm{O}$ or $\mathrm{HNO}_{3}$ and $a_{i}$ is the radius the particle would have if only the $i$ species evaporated. The amount of mass of species $i$ that is evaporated, $d m_{i}$, is then calculated from $(4 / 3) \pi \rho\left(a_{i}^{3}-a_{0}^{3}\right)$. The new total mass and radius of the STS particle are now

$m=m_{0}+\sum_{i} d m_{i}, \quad a=\sqrt[3]{\frac{m}{4 \pi \rho}}$.

Equations (9) and (10) are calculated $x$ times until $x d t$ equals the time the particles spend in the inlet. For each time step the new vapor pressure, density, latent heat, modified diffusion coefficient, modified thermal conductivity and particle temperature are calculated. For any one initial size, the model preserves the initial number concentration as that size is reduced by evaporation. This model is therefore Lagrangian in radius space.

\subsection{Details of the NAT model}

At low temperatures the growth and evaporation of NAT particles is governed by $\mathrm{HNO}_{3}$ partial pressure as long as $\mathrm{H}_{2} \mathrm{O}$ is supersaturated with respect to NAT. In this region it can be assumed that for every $\mathrm{HNO}_{3}$ molecule that evaporates, three $\mathrm{H}_{2} \mathrm{O}$ molecules evaporate. Equation (1) can now be written:

$a \frac{d a}{d t}=\frac{C D_{n}^{\star} M_{n}}{R \rho}\left(\frac{P_{p, n}}{T_{\infty}}-\frac{P_{s, n}}{T_{a}}\right) \frac{3 M_{w}+M_{n}}{M_{n}}$.

At warmer temperatures the same assumption is made although it is less certain. Laboratory investigations of a NAT particle as it is brought to temperatures much higher than its equilibrium temperature at stratospheric temperature and partial pressures are not available.

From the point where the temperature is high enough that $\mathrm{H}_{2} \mathrm{O}$ is no longer supersaturated with respect to NAT and the saturation ratio of $\mathrm{H}_{2} \mathrm{O}$ is less than the saturation ratio of $\mathrm{HNO}_{3}$ we assume that as three $\mathrm{H}_{2} \mathrm{O}$ molecules evaporate, one $\mathrm{HNO}_{3}$ molecule evaporates. The rate of evaporation is thus only dependent on evaporation of $\mathrm{H}_{2} \mathrm{O}$ and Eq. (1) is now

$a \frac{d a}{d t}=\frac{C D_{w}^{\star} M_{w}}{R \rho}\left(\frac{P_{p, w}}{T_{\infty}}-\frac{P_{s, w}}{T_{a}}\right) \frac{M_{w}+\frac{1}{3} M_{n}}{M_{w}}$.

The capacitance factor $C$ in Eqs. (11) and (12) is here 1.61 (Larsen, 2000) and the density of the NAT particles is assumed to be $1620 \mathrm{~kg} \mathrm{~m}^{-3}$ (Taesler et al., 1975). Surface tension (used in the Kelvin effect) between NAT and air is taken from Drdla and Turco (1991).

The vapor pressure of $\mathrm{H}_{2} \mathrm{O}$ and $\mathrm{HNO}_{3}$ over NAT at low temperatures are well documented (e.g. Hanson and Mauersberger, 1988b,a; Worsnop et al., 1993). An expression for vapor pressure of $\mathrm{HNO}_{3}$ as a function of temperature and 


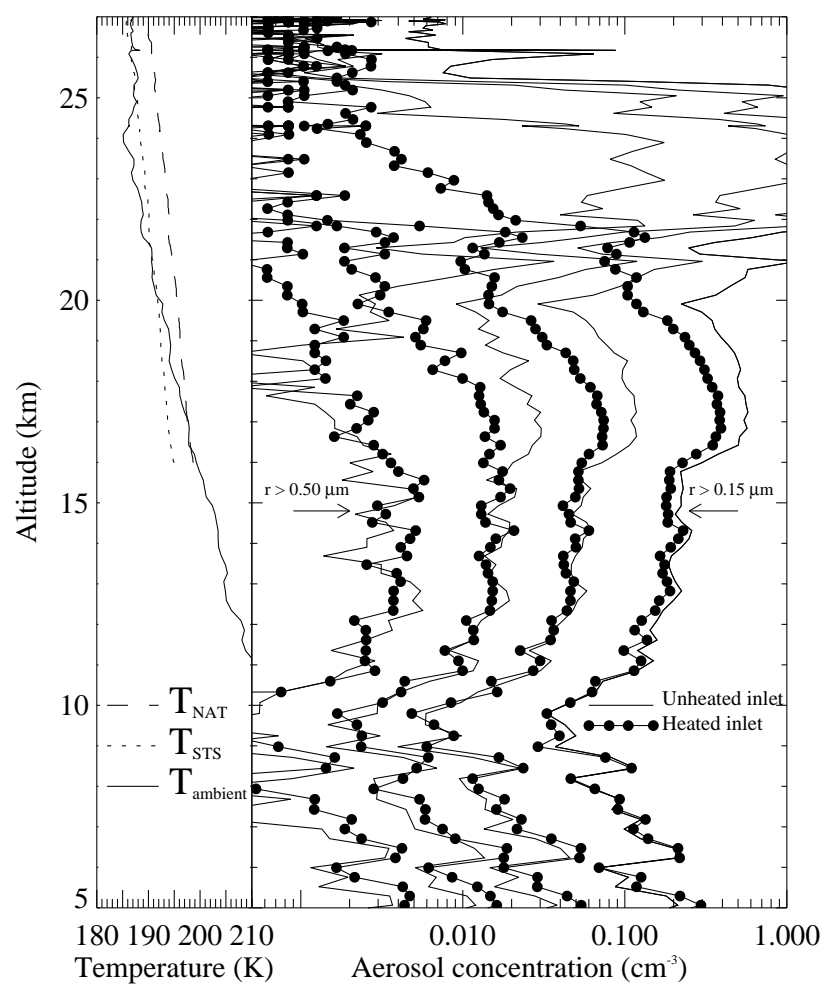

Fig. 1. Vertical profiles, $5-27 \mathrm{~km}$, of ambient temperature and of aerosol concentration for particles with radius $>0.15,0.25,0.30$, $0.50 \mu \mathrm{m}$, as measured by the ambient (lines) and $\sim 290 \mathrm{~K}$ heated (lines and data points) inlet OPCs flown on 6 December 2002. The temperature is compared to equilibrium temperatures for NAT and STS using the measured $\mathrm{H}_{2} \mathrm{O}$ concentration (Deshler et al., 2003b) and 11 ppbv $\mathrm{HNO}_{3}$.

$\mathrm{H}_{2} \mathrm{O}$ partial pressure in the temperature range 180 to $200 \mathrm{~K}$ is given in Hanson and Mauersberger (1988b). This expression can be used as long as $\mathrm{H}_{2} \mathrm{O}$ is saturated with respect to NAT. However, as far as we know, there are no vapor pressure expressions as a function of only temperature based on experiments at higher temperatures for NAT particles. Therefore, we have developed an expression based on Toon et al.'s (1986, Fig. 1) extrapolation of vapor pressure curves from measured partial pressures of $\mathrm{H}_{2} \mathrm{O}$ and $\mathrm{HNO}_{3}$ over a liquid solution (Clavelin and Mirabel, 1979). Below the melting point the slopes of the partial pressure curves were changed in proportion to the latent heat of fusion for the trihydrate. This results in lower vapor pressures than for the liquid particle with mass-fraction of $0.54 \mathrm{HNO}_{3}$. Toon et al. (1986) also extrapolated vapor pressures from the melting point by using the latent heat of the pure material $\left(\mathrm{H}_{2} \mathrm{O}\right.$ or $\left.\mathrm{HNO}_{3}\right)$. This approach gives slightly higher vapor pressures than by using the latent heat of the trihydrate. Toon et al. (1986) mentioned that the correct vapor pressure may lie between the two cases.

\subsection{Temperature and flow in the inlet}

There were two temperature sensors along the heated inlet. The first sensor was on the wall at the center of the heated inlet and was used to control the inlet temperature. The second temperature sensor was fixed to the inlet wall at the end of the inlet just before the optical chamber. In 2001, at the times we are interested in, the center temperature was about $255 \mathrm{~K}$. Over these times, the temperature at the end of the inlet decreased from about $251 \mathrm{~K}$ to about $243 \mathrm{~K}$. In 2002 the center temperature was around $303 \mathrm{~K}$ and the temperature at the end of the inlet was about $270 \mathrm{~K}$. In the models we have assumed that the particles experience a mean wall temperature which lies between the two temperatures.

The particle measurements were collected every $10 \mathrm{~s}$ and then averaged over homogeneous regions of the PSC. Averaging of the data is especially important for measurements from the heated inlet. The flow is assumed to have a Poiseuille flow distribution. Thus particles will experience different evaporation rates depending on where in the inlet the particles are situated. A particle closer to the center of the inlet will have a higher velocity, and thus evaporate less, than a particle closer to the wall that has a lower velocity. Averaging measurements over homogeneous cloud regions results in size distributions representative of about 40 samples and these particles will presumably be distributed similarly across the inlet for each sample. Thus the mean velocity of $7.8 \mathrm{~m} \mathrm{~s}^{-1}$ that the particles experience in the inlet is used.

The heated and ambient inlets for the 2002 measurements were both oriented vertically. In this orientation the sampling is nearly isokinetic. In 2001 both inlets were oriented horizontally. While this causes a sampling bias, both inlets suffer the same bias so a comparison of the two measurements is still justified.

\section{PSC and background aerosol observations}

In December 2001 the balloon-borne gondola, released from Esrange, Sweden $\left(68^{\circ} \mathrm{N}, 21^{\circ} \mathrm{E}\right)$, flew through a PSC located between 22 and $26 \mathrm{~km}$ (Deshler et al., 2003b). This cloud consisted of distinct layers of NAT, STS and a thin layer of ice. Below $24.5 \mathrm{~km}$ the particles were mainly STS and above they were mainly NAT. In December 2002 the balloon-borne gondola flew through a PSC located between 20 and $26 \mathrm{~km}$. This cloud consisted mainly of STS particles (Larsen et al., 2004).

Measurements with the ambient inlet OPC in these PSCs indicate bimodal size distributions in both NAT and STS layers. Some size distributions have a well developed second mode and a first mode which differs only slightly from SSA. Such distributions were observed at cloud top in both 2001 and 2002 and we believe they consist almost exclusively of NAT and SSA. In contrast, in a PSC with STS, the distribution is well developed in both the first and second mode. 
Deshler et al. (2003b) provide examples of both these types of distributions as well as intermediate distributions. The predominately STS and the intermediate distributions are probably characteristic of mixed phase clouds.

The difference in the distributions dominated by NAT and by STS are due to a nucleation barrier that exists for NAT particles (Zhang et al., 1996; Koop et al., 1997; Carslaw et al., 1998). STS particles do not have this barrier thus all small particles can grow into STS particles. Measurements from the heated inlet OPC in 2001 indicated bimodal size distributions if the PSC layer contained a second mode in its size distribution. This means that the largest particles did not evaporate back to SSA. In the 2002 flight, when the inlet temperature was increased, the evaporated size distribution consisted mostly of one mode, indicating complete evaporation (evaporation to SSA) of the condensed water and nitric acid.

Measurements outside of a PSC with the two OPCs offer a good test of the precision of the OPC measurements, since, if SSA are relatively unaffected by the heating, the heated and ambient inlet measurements should differ only slightly. At $247 \mathrm{~K}, w_{s} \sim 0.86$ (Steele and Hamill, 1981) while $w_{s}$ at ambient temperatures is lower. Thus SSA in the heated inlet will be slightly smaller than ambient SSA since water has evaporated; however, the difference is expected to be small. This small difference in size will slightly reduce concentrations from the heated inlet measurements when the two measurements are compared at the same size.

The agreement of aerosol volume from heated and ambient measurements on the boundaries of the PSC measured in 2001 (Deshler et al., 2003b) and the concentration profiles at 4 sizes in Fig. 1 from the 2002 heated and ambient measurements support these expectations. The 2002 measurements in Fig. 1 are in good agreement below $16 \mathrm{~km}$ with the heated inlet concentrations slightly less than the ambient concentrations. The PSC is clearly evident between 20 and $26 \mathrm{~km}$. Between 16 and $20 \mathrm{~km}$ the heated inlet measurements show a decrease of $\sim 50 \%$ in concentration at the smaller sizes. This is greater than would be expected due to drying of SSA in the heated inlet and temperatures are too warm for STS.

Air temperature was measured with five sensors. For the profile shown in Fig. 1 four of the five sensors agreed, to within $< \pm 0.5 \mathrm{~K}$, the precision of the measurement, while the fifth was warmer. These measurements indicate, for the measured water vapor and $11 \mathrm{ppbv} \mathrm{HNO}_{3}$, that below $19.5 \mathrm{~km}$ the measured temperature was $>1 \mathrm{~K}$ above temperatures required for STS. While STS are unlikely between 16 and $20 \mathrm{~km}$, the temperature is below the NAT point, so the presence of PSC particles can not be ruled out.

\section{Model results and discussion}

Strict comparisons between model and observations are possible for cases when PSC particles do not evaporate com-

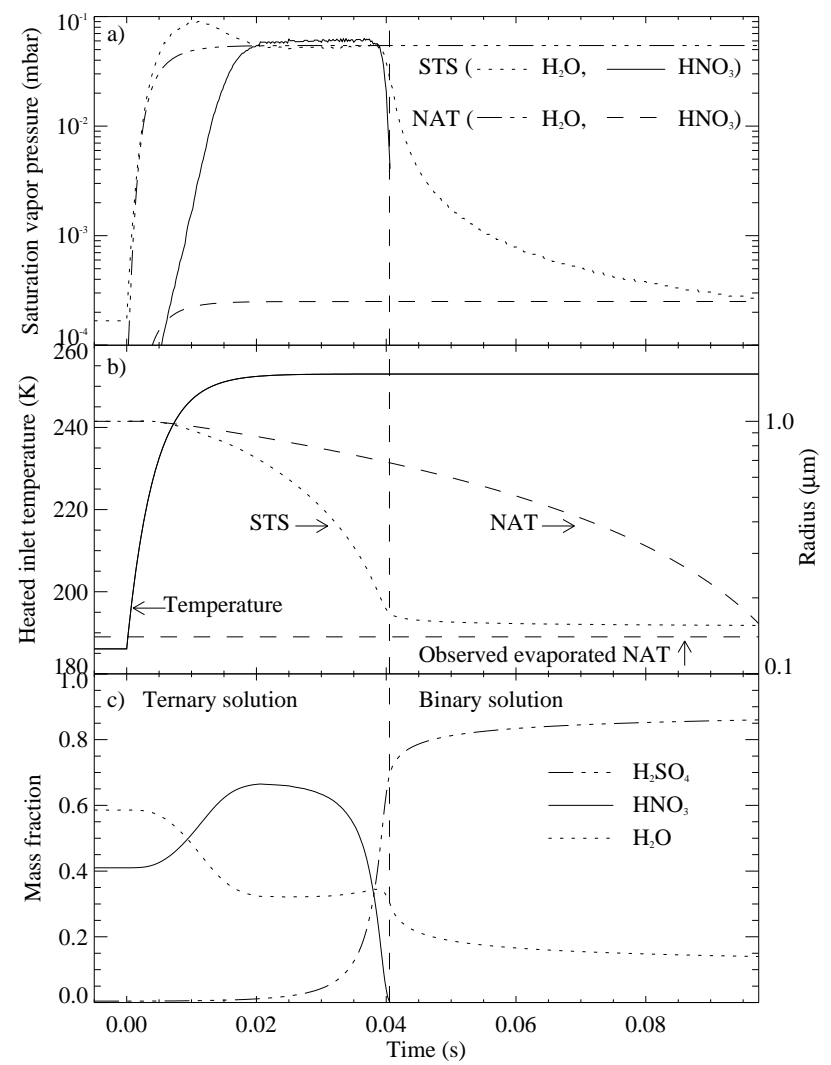

Fig. 2. Change of different variables along the heated inlet as STS and NAT particles evaporate. (a) Saturation vapor pressures of $\mathrm{H}_{2} \mathrm{O}$ and $\mathrm{HNO}_{3}$ over a $1 \mu \mathrm{m} \mathrm{STS}$ and NAT particle at $250 \mathrm{~K}$. (b) Temperature in the heated inlet (solid line) and particle size for STS (dotted line) and NAT (dashed line). The horizontal dashed line shows the observed size of a $1 \mu \mathrm{m}$ evaporated NAT particle. (c) Mass fraction of $\mathrm{H}_{2} \mathrm{O}, \mathrm{H}_{2} \mathrm{SO}_{4}$ and $\mathrm{HNO}_{3}$ for the STS particle.

pletely to SSA. Particles that evaporate completely may be checked against the model to see that it also predicts complete evaporation, but a strict test of the model requires measurements at a point in the heated inlet or at temperatures where evaporation is incomplete. Measurements in 2001 represent the latter case while particles in 2002 were completely evaporated.

\subsection{STS particle evaporation at $250 \mathrm{~K}$}

Variables such as temperature, saturation vapor pressure, particle size and particle mass fraction change in the inlet as STS particles evaporate. Figure 2 shows the modeled changes in these variables for a $1 \mu \mathrm{m}$ STS particle along the heated inlet. Figure $2 \mathrm{a}$ shows the saturation vapor pressure of $\mathrm{H}_{2} \mathrm{O}$ (dotted line) and $\mathrm{HNO}_{3}$ (solid line) over the STS particle. The change in the inlet temperature (solid line) and particle size (dotted line) is shown in Fig. 2b. As can be seen, the STS particle evaporates back to SSA in about $0.04 \mathrm{~s}$. Figure $2 \mathrm{c}$ shows the change of mass fraction of $\mathrm{HNO}_{3}, \mathrm{H}_{2} \mathrm{O}$ and $\mathrm{H}_{2} \mathrm{SO}_{4}$ as 


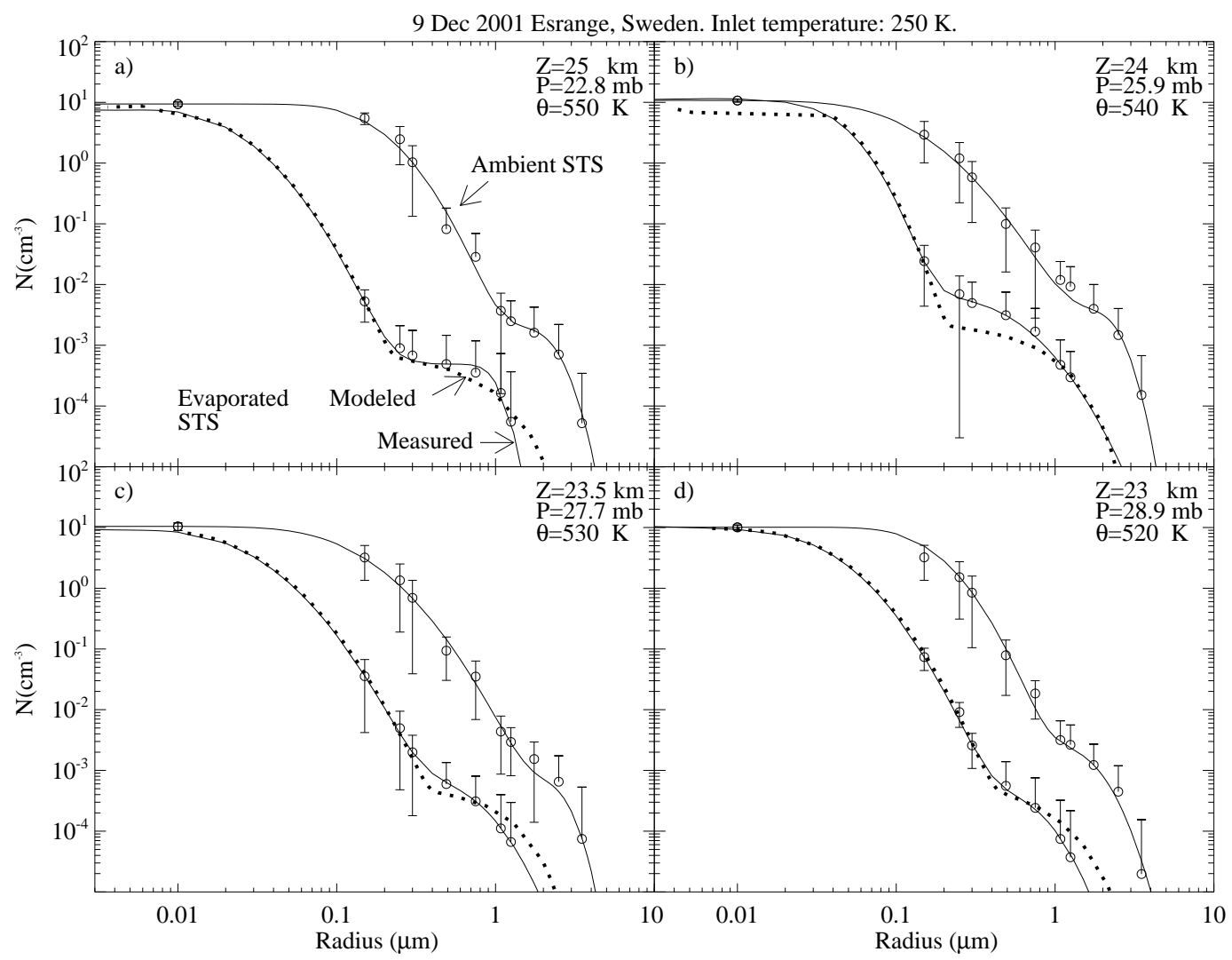

Fig. 3. Cumulative size distributions fitted to measured ambient STS particles, and to evaporated (measured and modeled) STS particles at $\sim 250 \mathrm{~K}$. The solid lines are the fitted size distributions. All measurements are averages over homogeneous cloud regions. The error bars are the standard deviation of the averaged measurements. Half error bars are used when the lower half of the error bar extends to the abscissa.

the STS particle passes through the inlet. This illustrates the large variations in mass fraction, with implications for saturation vapor pressure (see Fig. 2a), over the lifetime of a STS particle in the inlet. The mass fraction of $\mathrm{HNO}_{3}$ increases initially as more of the $\mathrm{H}_{2} \mathrm{O}$ evaporates. As the $\mathrm{HNO}_{3}$ mass fraction increases, the saturation vapor pressure of $\mathrm{HNO}_{3}$ will increase and evaporation of $\mathrm{HNO}_{3}$ will also increase. After $0.03 \mathrm{~s}$ in the inlet the mass fraction of $\mathrm{HNO}_{3}$ decreases rapidly.

Figure 3 shows ambient and evaporated STS particle measurements for four STS regions sampled in 2001 compared to the modeled evaporation. The measurements are shown as cumulative size distributions (the number concentration for a given size is the number of all particles greater than this size). The model fits well with observations in Figs. 3a, $3 \mathrm{c}$ and $3 \mathrm{~d}$. For Fig. $3 \mathrm{~b}$ the model shows too much evaporation compared to observations in the size range 0.2 to $1.0 \mu \mathrm{m}$. This may result if some of the particles are NAT, which evaporate slower than STS. Note that the heated inlet instrument did not measure particles larger than $1.25 \mu \mathrm{m}$. The fitted cumulative size distribution for particles larger than $1.25 \mu \mathrm{m}$ is thus estimated, and modeled and fitted size distributions can not be compared in this region.
Observations in 2001 showed that the second mode median radius of the predominantly STS cloud decreased by 55-80\% after passing through the heated inlet. In contrast, for measurements in predominantly NAT clouds, the median radius of the second mode decreased by $30-40 \%$. This suggests that NAT particles evaporate slower than STS particles. Therefore Fig. $3 \mathrm{~b}$ is probably not a representation of a homogeneous STS region in the cloud. The shapes of the PSC size distributions in Fig. 3 all show a weak second mode near $2 \mu \mathrm{m}$. This mode must result from a nucleation barrier, suggesting NAT mixed with the STS particles.

\subsection{STS particle evaporation at $290 \mathrm{~K}$}

In 2002 the temperature in the center of the inlet was increased to about $300 \mathrm{~K}$. The temperature at the end of the inlet was about $270 \mathrm{~K}$. The reason to increase the temperature for the 2002 case was to evaporate all PSC particles to SSA for microphysical modeling. The bend was also removed to omit any loss in the bend. In 2002 the PSC consisted mostly of STS droplets (Larsen et al., 2004). Figure 4 shows the comparison between the measurements and model at two different times during the flight. Figure 4a 


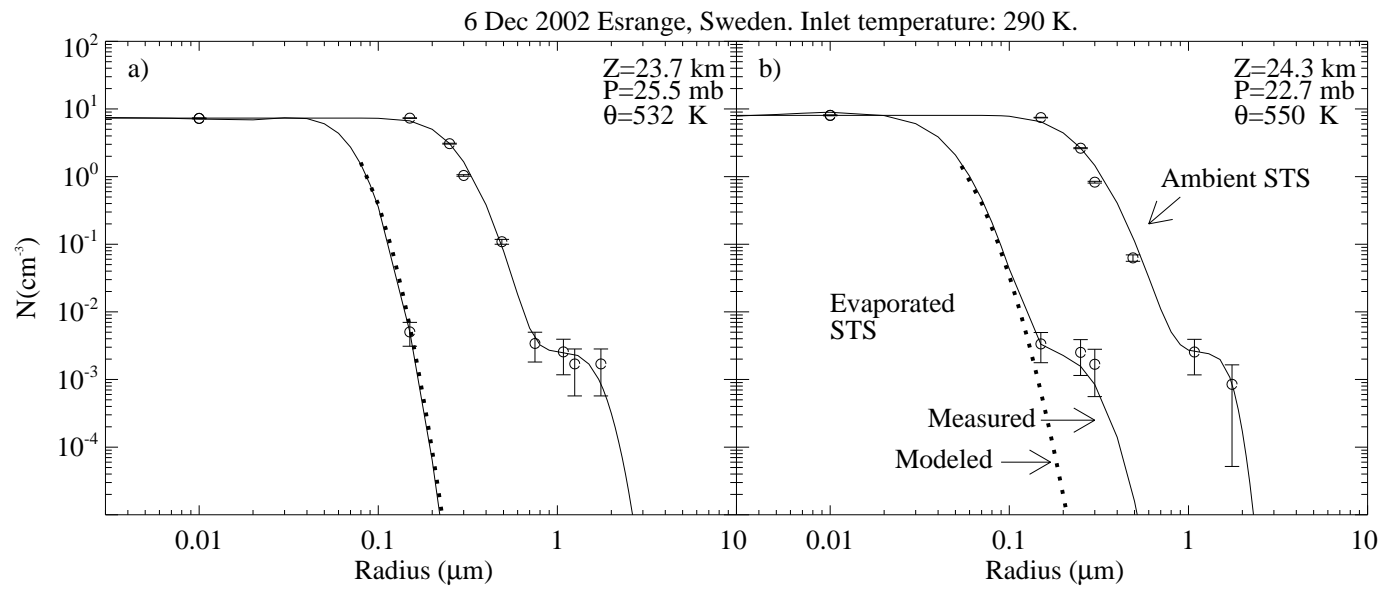

Fig. 4. Same as Fig. 3 but for measurements in 2002 where the inlet temperature was $\sim 290 \mathrm{~K}$. (a) shows an example of STS particles that have evaporated back to SSA while (b) shows an example of STS particles that have not evaporated completely. This part of the cloud probably also contained a few large NAT particles. The error bars for the 2002 case represent the Poisson counting error since these measurements are not averaged over homogeneous regions of the PSC, but rather represent a single 10 second integrated measurement.

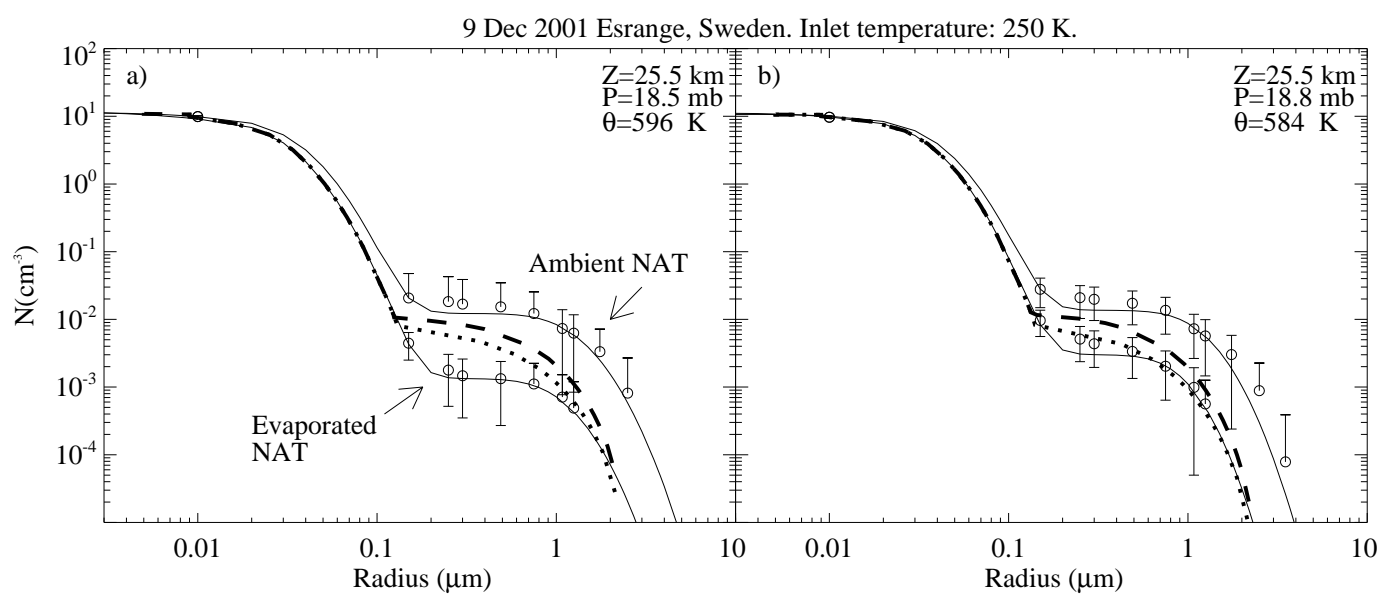

Fig. 5. Same as Fig. 3 but for averages over NAT layers sampled in 2001. Dashed line is modeled evaporation using vapor pressure for $\mathrm{HNO}_{3}$ and $\mathrm{H}_{2} \mathrm{O}$ extrapolated in proportion to the latent heat of fusion for the trihydrate. Dotted line is modeled evaporation where the vapor pressure for $\mathrm{HNO}_{3}$ and $\mathrm{H}_{2} \mathrm{O}$ is extrapolated for pure $\mathrm{HNO}_{3}$ and $\mathrm{H}_{2} \mathrm{O}$.

shows a measurement of PSC particles evaporating to SSA and is typical of over $80 \%$ of the measurements. In about $20 \%$ of the measurements, large particles did not evaporate completely even though the model predicted complete evaporation (Fig. 4b). Attempts to explain these observations by assuming that the inlet temperatures were at the minimum of the range measured, or that particles experienced the maximum flow, which is twice the mean flow, were unsuccessful. The second mode shown in the heated inlet observations are also not likely to be SSA. Above and below the cloud all size distributions show only one mode or a weak second mode (Deshler et al., 2003b). This is similar to other measurements of SSA in the Arctic (Deshler et al., 2000; Lee et al., 2003). The large particles are probably NAT particles which need a longer time to evaporate, suggesting that about $20 \%$ of the observations in 2002 were in a mixed phase cloud.

\subsection{NAT particle evaporation at $250 \mathrm{~K}$}

Figure 5 shows averages of measured ambient and evaporated particle size distributions over two NAT layers sampled in 2001. The modeled evaporation is calculated for the two extreme assumptions for $\mathrm{HNO}_{3}$ and $\mathrm{H}_{2} \mathrm{O}$ vapor pressures. The dashed line shows the modeled evaporation using the vapor pressures extrapolated from the latent heat of trihydrate. This modeled evaporation of NAT particles from about 1 to $3 \mu \mathrm{m}$ shows insufficient evaporation compared to observations. The dotted line shows the result for vapor pressures extrapolated using the latent heat of the pure materials. In 
this case the model is closer to the measurements, however, the correct evaporation may lie between these extreme assumptions about the vapor pressures. The two models converge for evaporated particles larger than $1.5-2 \mu \mathrm{m}$. In this size region, the change of radius due to evaporation is low and the apparently large decrease in radius is due to loss of particles in the bend. Thus the concentration of large particles decreases, but not due to evaporation.

Figure 2 shows the modeled change in saturation vapor pressures and size for a $1 \mu \mathrm{m}$ NAT particle. The vapor pressures from extrapolating $\mathrm{HNO}_{3}$ and $\mathrm{H}_{2} \mathrm{O}$ saturation vapor pressures in proportion to the latent heat of fusion for the pure $\mathrm{HNO}_{3}$ and $\mathrm{H}_{2} \mathrm{O}$ are assumed in this case. The horizontal dashed line show the measured evaporated size related to the $1 \mu \mathrm{m}$ measured NAT particle. Since the composition of NAT is assumed to remain constant, the saturation vapor pressures over NAT are only a function of particle temperature. Therefore, as the particle temperature becomes constant, the saturation vapor pressures do not change (Fig. 2a).

It has been suggested that rapid heating in the inlet could cause solid NAT particles to instantaneously melt; however, this is not supported by the model. Using the STS model for predominately NAT distributions, assuming that the NAT particles liquefy, causes an over prediction of measured evaporation.

Evaporation of a solid NAT particle that does not maintain its 3:1 stoichiometry is not considered since we are not aware of an expression for vapor pressures for a frozen $\mathrm{HNO}_{3}$ $\mathrm{H}_{2} \mathrm{O}-\mathrm{H}_{2} \mathrm{SO}_{4}$ particle as a function of temperature and mass fraction.

\section{Conclusions}

Models have been developed to simulate evaporation of STS and NAT particles at high temperatures but stratospheric partial pressures. The models were initialized with in situ size distribution measurements of STS and NAT particles and compared to measurements of evaporated STS and NAT particles.

When the evaporation chamber was heated to about $250 \mathrm{~K}$ (2001), PSC particles do not completely evaporate to SSA and the model reproduces the observations in predominately STS layers. There is, however, some discrepancy for the largest particles in these layers which are most likely NAT particles. The NAT model, however, calculates insufficient evaporation compared to observations even when the vapor pressures, found by extrapolating vapor pressure from the melting point using latent heat of pure materials, were used.

For an evaporation chamber at about $290 \mathrm{~K}$ (2002), STS particles were expected to completely evaporate to SSA. This was confirmed by measurement and model. The model, however, can only confirm that complete evaporation occurred. Since it is impossible to know where in the inlet complete evaporation occurred this case is a less stringent test of the model. For $\sim 20 \%$ of the measurements at $290 \mathrm{~K}$ there were a few large particles which did not completely evaporate. These probably represent the measurements of a few large NAT particles in these regions of the cloud.

For NAT particles in the 2001 case we are still uncertain how the particles behave at high temperatures but with stratospheric partial pressures. When it is assumed that the composition of the trihydrate does not change, the model shows insufficient evaporation compared to measurements. To model this case properly requires an expression for $\mathrm{H}_{2} \mathrm{O}$ and $\mathrm{HNO}_{3}$ vapor pressure as function of temperature and mass fraction for the frozen $\mathrm{HNO}_{3}-\mathrm{H}_{2} \mathrm{O}-\mathrm{H}_{2} \mathrm{SO}_{4}$ particle.

Overall the heater was found to do an adequate job of evaporating PSC particles back to their SSA origins, and the model developed here to do an adequate job of reproducing the observations within reasonable assumptions. The evaporation and our understanding of it becomes relatively less certain for NAT than for STS. The largest unknowns for the model are the actual temperature the particles experience as they pass through the inlet and the vapor pressures over NAT particles at high temperature. One surprising result is the observation that the evaporation measurement may be able to uncover a small fraction of NAT particles embedded in predominantly STS clouds.

Acknowledgements. Thanks to C. Wilson for originally suggesting we include a heated inlet measurement on the gondola and to $\mathrm{N}$. Larsen for helpful comments on this paper. The excellent balloon operations were completed by the Centre National d'Etudes Spatiales with support from the Swedish Space Corporation. This research was supported by the Commissions of the European Union through the Environmental and Climate program and the U.S. National Science Foundation (OPP-0095158).

Edited by: K. Carslaw

\section{References}

Bejan, A.: Convective heat transfer, John Wiley \& Sons Inc., 1984. Carslaw, K. S., Luo, B. P., Clegg, S. L., Peter, T., Brimblecombe, P., and Crutzen, P. J.: Stratospheric aerosol growth and $\mathrm{HNO}_{3}$ gas phase depletion from coupled $\mathrm{HNO}_{3}$ and water uptake by liquid particles, Geophys. Res. Lett., 21, 2479-2482, 1994.

Carslaw, K. S., Luo, B., and Peter, T.: An analytical expression for the composition of aqueous $\mathrm{HNO}_{3}-\mathrm{H}_{2} \mathrm{SO}_{4}$ stratospheric aerosols including gas phase removal of $\mathrm{HNO}_{3}$, Geophys. Res. Lett., 22, 1877-1880, 1995.

Carslaw, K. S., Wirth, M., Tsias, A., Luo, B. P., Dörnbrack, A., Leutbecher, M., Volkert, H., Renger, W., Bacmeister, J. T., and Peter, T.: Particle microphysics and chemistry in remotely observed mountain polar stratospheric clouds, J. Geophys. Res., 103, 5785-5796, 1998.

Clavelin, J. L. and Mirabel, P.: Determination des pressions partielles du melange eau-acide nitirque, J. De Chimie Physi, 76, 533-537, 1979. 
Clegg, S. L., Brimblecombe, P., and Wexler, A. S.: A thermodynamic model of the system $\mathrm{H}^{+}-\mathrm{NH}_{4}^{+}-\mathrm{SO}_{4}^{2-}-\mathrm{NO}_{3}^{-}-\mathrm{H}_{2} \mathrm{O}$ at tropospheric temperatures, J. Phys. Chem, 102A, 2137-2154, 1998.

Deshler, T., Nardi, B., Adriani, A., Cairo, F., Hansen, G., Fierli, F., Hauchecorne, A., and Pulvirenti, L.: Determining the index of refraction of polar stratospheric clouds above Andoya $\left(69^{\circ} \mathrm{N}\right)$ by combining size-resolved concentration and optical scattering measurements, J. Geophys. Res., 105, 3943-3953, 2000.

Deshler, T., Hervig, M. E., Hofmann, D. J., Rosen, J. M., and Liley, J. B.: Thirty years of in situ stratospheric size distribution measurements from Laramie, Wyoming $\left(41^{\circ} \mathrm{N}\right)$, using balloon-borne instruments, J. Geophys. Res., 108, 4167, doi:10.1029/2002JD002514, 2003a.

Deshler, T., Larsen, N., Weissner, C., Schreiner, J., Mauersberger, K., Cairo, F., Adriani, A., Donfrancesco, G. D., Ovarlez, J., Ovarlez, H., Blum, U., Fricke, K. H., and Dörnbrack, A.: Large nitric acid particles at the top of an Arctic stratospheric cloud, J. Geophys. Res., 108, 4517, doi:1029/2003JD003479, 2003 b.

Drdla, K. and Turco, R. P.: Denitrification trough PSC formation: A 1-D model incorporating temperature oscillations, J. Atmos. Chem., 12, 319-366, 1991.

Dye, J. E., Baumgardner, D., Gandrud, B. W., Kawa, S. R., Kelly, K. K., Loewenstein, M., Ferry, G. V., Chan, K. R., and Gary, B. L.: Particle size distribution in Arctic polar stratospheric clouds, growth and freezing of sulfuric acid droplets and implications for cloud formation, J. Geophys. Res., 97, 8015-8034, 1992.

Fahey, D. W., Gao, R. S., Carslaw, K. S., Kettleborough, J., Popp, P. J., Northway, M. J., Holecek, J. C., Ciciora, S. C., McLaughlin, R. J., Thompson, T. L., Winkler, R. H., Baumgardner, D. G., Gandrud, B., Wennberg, P. O., Dhaniyala, S., McKinney, K., Peter, T., Salawitch, R. J., Bui, T. P., Elkins, J. W., Webster, C. R., Atlas, E. L., Jost, H., Wilson, J. C., Herman, R. L., Kleinböhl, A., and von König, M.: The detection of large $\mathrm{HNO}_{3}$-containing particles in the winter Arctic stratosphere, Science, 291, 10261031, 2001.

Fuchs, N. and Sutugin, A.: Highly dispersed aerosols, in Topics in current aerosol research, Pergamon Press, New York, 1971.

Giaugue, W. F., Hornung, E. W., Kunzler, J. E., and Rubin, T. R.: The thermodynamic properties of aqueous sulfuric acid solutions and hydrates from 15 to $300^{\circ}$, J. Am. Chem. Soc, 82, 62-70, 1960.

Gmitro, J. I. and Vermeulen, T.: Vapor-liquid equilibria for aqueous sulfuric acid, A.I.Ch.E.J., 10, 740-746, 1964.

Goodman, J., Toon, O. B., Pueschel, R. F., Snetsinger, K. G., and Verma, S.: Antarctic stratospheric ice crystals, J. Geophys. Res., 94, 16449-16457, 1989.

Goodman, J., Verma, S., Pueschel, R. F., Ferry, G. V., and Webster, D.: New evidence of size and composition of polar stratospheric cloud particles, Geophys. Res. Lett., 24, 615-618, 1997.

Granzhan, V. and Laktionova, S.: The densities, viscosities, and surface tensions of aqueous nitric acid solutions, Russian J. Phys. Chem, 49, 1448, 1975.

Hamill, P., Toon, O. B., and Kiang, C. S.: Microphysical processes affecting stratospheric aerosol particles, J. Atmos. Sci., 34, 1104-1119, 1977.

Hanson, D. R. and Mauersberger, K.: Vapor pressures of $\mathrm{HNO}_{3} / \mathrm{H}_{2} \mathrm{O}$ solutions at low temperatures, J. Phys. Chem., 92, 6167-6170, 1988a.
Hanson, D. R. and Mauersberger, K.: Laboratory studies of the nitric acid trihydrate: Implication for the south polar stratosphere, Geophys. Res. Lett., 15, 855-858, 1988 b.

Hinds, W.: Aerosol technology, properties, behavior and measurements of airborne particles, A Wiley-Interscience publication, 1999.

Koop, T., Luo, B. P., Biermann, U. M., and Crutzen, P. J.: Freezing of $\mathrm{HNO}_{3} / \mathrm{H}_{2} \mathrm{SO}_{4} / \mathrm{H}_{2} \mathrm{O}$ solutions at stratospheric temperatures: Nucleation statistics and experiments, J. Phys. Chem. A., 101, 1117-1133, 1997.

Larsen, N.: Polar stratospheric clouds microphysical and optical models, Danish Meteorological Institute, scientific report 00-06, 2000.

Larsen, N., Knudsen, B. M., Svendsen, S. H., Deshler, T., Rosen, J. M., Kivi, R., Weisser, C., Schreiner, J., Mauersberger, K., Cairo, F., Ovarlez, J., Oelhaf, H., and Spang, R.: Formation of solid particles in synoptic-scale Arctic PSCs in early winter 2002/2003, Atmos. Chem. Phys., 4, 2001-2013, 2004,

SRef-ID: 1680-7324/acp/2004-4-2001.

Lee, S. H., Reeves, J. M., Wilson, J. C., Hunton, D. E., Viggiano, A. A., Miller, T. M., Ballenthin, J. O., and Lait, L. R.: Particle formation by ion nucleation in the upper troposphere and lower stratosphere, Science, 301, 1886-1889, 2003.

Luo, B., Krieger, U., and Peter, T.: Densities and refractive indices of $\mathrm{H}_{2} \mathrm{SO}_{4} / \mathrm{HNO}_{3} / \mathrm{H}_{2} \mathrm{O}$ solutions to stratospheric temperatures, Geophys. Res. Lett., 23, 3707-3710, 1996.

Luo, B. P., Voigt, C., Fueglistaler, S., and Peter, T.: Extreme NAT supersaturations in mountain wave ice PSCs: A clue to NAT formation, J. Geophys. Res., 108, 4441, doi:10.1029/2002JD003104, 2003.

Meilinger, S. K., Koop, T., Luo, B. P., Huthwelker, T., Carslaw, K. S., Krieger, U., Crutzen, P. J., and Peter, T.: Size-dependent stratospheric droplet composition in lee wave temperature fluctuations and their potential role in PSC freezing, Geophys. Res. Lett., 22, 3031-3034, 1995.

Pruppacher, H. and Klett, J.: Microphysics of clouds and precipitation, Kluwer Academic Publisher, 1997.

Schreiner, J., Voigt, C., Kohlmann, A., Arnold, F., Mauersberger, K., and Larsen, N.: Chemical analysis of polar stratospheric cloud particles, Science, 283, 968-970, 1999.

Schreiner, J., Voigt, C., Zink, P., Kohlmann, A., Knopf, D., Weisser, C., Budz, P., and Mauersberger, K.: A mass spectrometer system for analysis of polar stratospheric aerosols., Rev. Sci. Inst., 73, 446-452, 2002.

Solomon, S., Garcia, R. R., Rowland, F. S., and Wuebbles, D. J.: On the depletion of Antarctic ozone, Nature, 321, 755-758, 1986.

Steele, H. M. and Hamill, P.: Effects of temperature and humidity on the growth and optical properties of sulphuric acid-water droplets in the stratosphere, J. Aerosol Sci., 12, 517-528, 1981.

Tabazadeh, A., Turco, R. P., Drdla, K., and Jacobsen, M. Z.: A study of type I polar stratospheric cloud formation, Geophys. Res. Lett., 21, 1619-1622, 1994.

Tabazadeh, A., Martin, S., and Lin, J.: The effect of particle size and nitric acid uptake on the homogeneous freezing of aqueous sulfuric acid particles, Geophys. Res. Lett., 27, 111-1114, 2000.

Taesler, I., Delaplane, R. G., and Olovsson, I.: Hydrogen bond studies, XCIV. Diaquaoxonium Ion in nitric acid trihydrate, Acta. Cryst, B 31, 1489-1492, 1975. 
Tolbert, M. A., Rossi, M. J., and Golden, D. M.: Heterogeneous interactions of chlorine nitrate hydrogen chloride and nitric acid with sulfuric acid surfaces at stratospheric temperatures, Geophys. Res. Lett., 15, 847-850, 1988.

Toon, O. B., Hamill, P., Turco, R. P., and Pinto, J.: Condensation of $\mathrm{HNO}_{3}$ and $\mathrm{HCl}$ in the winter polar stratospheres, Geophys. Res. Lett., 13, 1284-1287, 1986.

Toon, O. B., Turco, R. P., Jordan, J., Goodman, J., and Ferry, G.: Physical processes in polar stratospheric ice clouds, J. Geophys. Res., 94, 11359-11380, 1989.
Voigt, C., Schreiner, J., Kohlmann, A., Mauersberger, K., Larsen, N., Deshler, T., Kröger, C., Rosen, J., Adriani, A., Cairo, F., Di Donfrancesco, G., Viterbini, M., Orvalez, J., Orvalez, H., David, C., and Dörnbrack, A.: Nitric acid trihydrate (NAT) in polar stratospheric cloud particles, Science, 290, 1756-1758, 2000.

Worsnop, D. R., Fox, L. E., Zahniser, M. S., and Wofsy, S. C.: Vapor pressures of solid hydrates of nitric acid: implications for polar stratospheric clouds, Science, 259, 71-74, 1993.

Zhang, R., Leu, M. T., and J., M. M.: Formation of polar stratospheric clouds on preactivated background aerosols, Geophys. Res. Lett., 23, 1669-1672, 1996. 